\title{
Association of CYP7A1 -278A $>C$ polymorphism and the response of plasma triglyceride after dietary intervention in dyslipidemic patients
}

\author{
A.L.V. Barcelos ${ }^{1}$, R. Chies $^{2}$, S.E.M. Almeida ${ }^{3,6}$, M. Fiegenbaum ${ }^{4}$, I.D. Schweigert ${ }^{5}$, \\ F.G.L. Chula6 ${ }^{6}$ M.L. Rossetti ${ }^{1,6}$ and C.M.D. Silva1,2,6 \\ ${ }^{1}$ Curso de Pós-graduação em Genética e Toxicologia Aplicada, ${ }^{2}$ Curso de Pós-graduação em \\ Diagnóstico Genético e Molecular, Universidade Luterana do Brasil (ULBRA), Canoas, RS, Brasil \\ ${ }^{3}$ Centro Universitário Feevale, Instituto da Saúde, Novo Hamburgo, RS, Brasil \\ ${ }^{4}$ Centro Universitário Metodista IPA, Porto Alegre, RS, Brasil \\ ${ }^{5}$ Departamento de Medicina Interna, Faculdade de Medicina, Universidade Federal do Rio Grande do \\ Sul, Porto Alegre, RS, Brasil \\ ${ }^{6}$ Centro de Desenvolvimento Científico e Tecnológico, Fundação Estadual de Produção e Pesquisa em \\ Saúde, Porto Alegre, RS, Brasil
}

Correspondence to: C.M.D. Silva, Centro de Desenvolvimento Científico e Tecnológico, Fundação Estadual de Produção e Pesquisa em Saúde, Av. Ipiranga, 5400, 90610-000 Porto Alegre, RS, Brasil Fax:+55-51-3352-0336. E-mail: cmdornelles@terra.com.br

\begin{abstract}
We investigated the effect of the $-278 \mathrm{~A}>\mathrm{C}$ polymorphism in the CYP7A1 gene on the response of plasma lipids to a reduced-fat diet for 6 to 8 weeks in a group of 82 dyslipidemic males with a mean age of $46.0 \pm 11.7$ years. Individuals who presented at least one high alteration in total cholesterol, low-density lipoprotein cholesterol or triglyceride values were considered to be dyslipidemic. Exclusion criteria were secondary dyslipidemia due to diabetes mellitus, renal, liver, or thyroid disease. None of the subjects were using lipid-lowering medication. Baseline and follow-up lipid concentrations were measured. The genotypes were determined by the digestion of PCR products with the Bsal restriction endonuclease. There were statistically significant reductions in plasma total cholesterol, low-density lipoprotein cholesterol and triglyceride concentrations after dietary intervention. The minor allele $C$ has a frequency of $43 \%$. Carriers of the $C$ allele had significantly lower triglyceride concentrations $(P=$ 0.02 ) than AA homozygotes. After adjustment of covariates, subjects with the AC and CC genotypes showed a greater reduction in triglyceride concentrations compared to subjects with the AA genotype. Multiple linear regression analyses showed that the AC and CC CYP7A1 genotypes accounted for 5.2 and $6.2 \%$ of triglyceride concentration during follow-up and adjusted percent of change of triglyceride concentration, respectively. The present study provides evidence that $-278 \mathrm{~A}>\mathrm{C}$ polymorphism in the CYP7A1 gene can modify triglyceride concentrations in response to a reduced fat diet in a dyslipidemic male population. This gene represents a potential locus for a nutrigenetic directed approach.
\end{abstract}

Key words: Dyslipidemia; Polymorphisms; Diet; CYP7A1; Southern Brazil

Research supported by ULBRA, PADCT/FEPPS.

Received September 5, 2008. Accepted March 3, 2009 


\section{Introduction}

Dyslipidemia is a multifactorial disorder in which nutritional factors are closely related to a number of the manifestations of the disease. Clinical trials involving dietary interventions to reduce plasma concentrations of lipids and lipoproteins have demonstrated favorable responses by dyslipidemic individuals, including a decreased risk of cardiovascular disease $(1,2)$. However, the response of plasma lipids to dietary interventions shows considerable interindividual variations, supporting the view that genediet interactions modulate plasma lipid concentrations and potentially cardiovascular risk (3).

Several studies have shown that this varied response is associated with common polymorphisms in candidate genes related to lipid metabolism (4). Genetic variations in the CYP7A1 gene, which encodes cholesterol 7alphahydroxylase, have been associated with metabolic disorders of cholesterol and bile acids, including hypercholesterolemia, hypertriglyceridemia, atherosclerosis, and gallstone disease (5-15). Cholesterol 7alpha-hydroxylase is the first enzyme to catalyze the reaction of the catabolic pathway of cholesterol. This catalytic reaction is the ratelimiting step and the major site regulating cholesterol homeostasis and bile acid synthesis in the liver (16).

Humans lacking cholesterol 7alpha-hydroxylase activity as a result of a mutation in the CYP7A1 gene have significant elevation of total and low-density lipoprotein (LDL) cholesterol concentrations, substantial accumulation of cholesterol in the liver, and a markedly decreased rate of bile acid excretion (17). Current genetic studies are mainly focused on the analysis of a single nucleotide polymorphism at $-278 \mathrm{~A}>\mathrm{C}$ ( $\mathrm{rs} 3808607)$ in the promoter region of the CYP7A1 gene (5-15). However, only few studies of the association of lipid diets with CYP7A1 $-278 \mathrm{~A}>\mathrm{C}$ polymorphism have been reported $(8,9,12)$.

Nutrigenetics is a concept that may contribute significantly to the prevention and treatment of disease. Identifying genetic polymorphisms that participate in significant gene-diet interaction may provide tools for personalized and more successful dietary recommendations. In the present study, we investigated the effect of the $-278 \mathrm{~A}>\mathrm{C}$ promoter polymorphism of the CYP7A1 gene on the response of plasma lipids to a reduction of dietary fat intake in a group of dyslipidemic males.

\section{Patients and Methods}

\section{Patients}

A total of 116 men with dyslipidemia were recruited for this study, but only 82 remained at the end. The Hospital de
Guarnição (Santo Angelo, Rio Grande do Sul, Brazil) Ethics Committee approved the study, and informed written consent was obtained from all participants. Lipid concentrations were classified according to the III Brazilian Guidelines on Dyslipidemia (18). Total cholesterol was defined as normal (<200 mg/dL), moderate (200-239 mg/ $\mathrm{dL}$ ) and high ( $\geq 240 \mathrm{mg} / \mathrm{dL}$ ). For LDL cholesterol, the following ranges were considered normal $(<130 \mathrm{mg} / \mathrm{dL})$, moderate (130-159 mg/dL) and high ( $\geq 160 \mathrm{mg} / \mathrm{dL})$. For highdensity lipoprotein (HDL) cholesterol, the following ranges were considered high ( $>60 \mathrm{mg} / \mathrm{dL}$ ) and low ( $<40 \mathrm{mg} / \mathrm{dL})$. For triglycerides, values above $200 \mathrm{mg} / \mathrm{dL}$ were considered to be high, values from 150 to $200 \mathrm{mg} / \mathrm{dL}$ were considered to be moderate and values below $150 \mathrm{mg} / \mathrm{dL}$ were considered to be normal. Individuals who presented at least one high alteration in these values were considered to be dyslipidemic. Exclusion criteria were secondary dyslipidemia due to diabetes mellitus or renal, liver or thyroid disease. No subject was taking lipid-lowering medication. All participants were instructed by a nutritionist to consume a low-fat diet for an intervention period of 6 to 8 weeks. All received a dietary guideline according to the National Cholesterol Education Program III (NCEP III) (19) and were asked to maintain this diet throughout the protocol. Dietary compliance was assessed from 15-day food records by examining food intake records, and questioning participants about their experience during the previous 2week period. The nutritionist repeatedly emphasized that participants should not modify their diets. Anthropometric measurements of waist circumference, weight and height were taken only at baseline and body mass index (BMI) was calculated.

\section{Biochemical analyses, DNA extraction and genotyping}

At the beginning and at the end of the study, blood samples were collected after a 12-h fast. Total plasma cholesterol, HDL cholesterol, and triglyceride concentrations were determined by standard enzymatic methods. LDL cholesterol was calculated by the method of Friedewald et al. (20).

DNA was isolated from whole blood by standard procedures (21). CYP7A1 genotyping was performed as previously described (22). Briefly, PCR was carried out in a reaction mixture of $10 \mu \mathrm{L}$ containing 0.5 units of Taq DNA polymerase and $1 \mu \mathrm{L}$ of template DNA with a concentration of 50 to $150 \mathrm{ng} / \mu \mathrm{L}$, using primers 5'-AATGTTTTTCCCAG TTCTCTTTC-3' (sense) and 5'-AATTAGCCATTTGTT CATTCTATTAG-3' (antisense). The PCR product of 393 bp was digested with 10 units of $B s a l$ in a reaction mixture of $20 \mu \mathrm{L}$ for $3 \mathrm{~h}$ at $50^{\circ} \mathrm{C}$. The digestion resulted in fragments of 300 and $93 \mathrm{bp}$ for the A allele, and in fragments of 261, 
93, and 39 bp for the $\mathrm{C}$ allele. The digested PCR products were submitted to $3 \%$ agarose gel electrophoresis and visualized by ethidium bromide staining.

\section{Statistical analysis}

Allele frequencies were estimated by the gene counting method. The agreement of genotype frequencies with Hardy-Weinberg expectations was tested using the $\chi^{2}$ test. Continuous variables are reported as means \pm SD. Multiple linear regression analyses were used to adjust lipid and lipoprotein variables and analysis of variance (ANOVA) was used to compare lipid concentrations between genotype groups. The interaction between the $-278 \mathrm{~A}>\mathrm{C}$ alleles and type of dyslipidemia on changes in lipid concentrations was tested by multiple regression analyses; age, BMI and baseline lipid concentrations were entered in each model as covariates. To reduce skewness, log-transformation of triglyceride concentrations was used in all analyses. The paired Student $t$-test or the Wilcoxon signed-rank test was used to test for differences in lipid concentrations before and after dietary intervention. Statistical analyses were carried out using the SPSS software package, version 13.0. The level of significance was set at $P<0.05$.

\section{Results}

Patients were divided into three dyslipidemic groups: hypercholesterolemic $(\mathrm{HC}, \mathrm{N}=19)$, hypertriglyceridemic (HTG, $N=10$ ) and mixed dyslipidemic (MD, $N=53$ ). The baseline and follow-up characteristics of the dyslipidemic patient groups are shown in Table 1. The age of the HTG group was significantly lower than the age of the $\mathrm{HC}$ and $\mathrm{MD}$ groups $(\mathrm{P}$ $=0.004)$. Moreover, BMI was significantly higher in the MD and HTG groups $(P=0.041)$. No differences in waist or hip circumferences were observed between patient groups. Baseline and follow-up lipid concentrations differed significantly between groups $(P<0.01$ for all lipid parameters).

Overall, there were statistically significant reductions in plasma total cholesterol, LDL cholesterol and triglyceride concentrations after dietary intervention (Table 2). The percentage dyslipidemia. of patients with high total cholesterol, LDL cholesterol and triglyceride concentrations was also reduced (53.0 vs 34.9, 47.0 vs 27.7 , and 56.6 vs $39.8 \%$, respectively).

The frequencies of the genotypes were in Hardy-Weinberg equilibrium and the minor $\mathrm{C}$ allele had a frequency of $43 \%$. No significant associations between genotypes and BMI $(P=0.10)$ or waist circumference $(P=0.29)$ were observed (data not shown). The effects of CYP7A1 genotype distribution on the response of plasma lipids before and after low-fat dietary interventions and mean percent reductions of lipid and lipoprotein concentrations are shown in Table 3. These results indicate that the CYP7A1 genotype exerts a significant influence on plasma triglyceride concentrations after dietary intervention. Carriers of the $C$ allele had significantly lower triglyceride concentrations $(P$ $=0.02 ; \mathrm{AC}, 188.9 \pm 99.9 \mathrm{mg} / \mathrm{dL} ; \mathrm{CC}, 163.4 \pm 116.1 \mathrm{mg} / \mathrm{dL})$ than AA homozygotes $(231.3 \pm 97.1 \mathrm{mg} / \mathrm{dL})$. After adjustment of covariates, the AC and CC genotypes showed a greater reduction in triglyceride concentrations compared to the AA genotype $(-12.9 \pm 35.2$ and $-13.9 \pm 32.5$ vs -4.9 $\pm 46.4 \%$; $P=0.04$ ). No associations of $-278 \mathrm{~A}>\mathrm{C}$ polymorphism with total cholesterol, LDL cholesterol or HDL cholesterol concentrations were observed. Multiple linear regression analyses showed that the AC and CC CYP7A1 genotypes accounted for 5.2 and $6.2 \%$ of tryglyceride concentration during follow-up and adjusted percent of change of triglyceride concentration, respectively (Table 4).

Since the baseline and follow-up lipid concentrations

Table 1. Baseline, post-intervention and changes in plasma lipids as a function of type of

\begin{tabular}{lccccr}
\hline & Total $(\mathrm{N}=82)$ & $\mathrm{HC}(\mathrm{N}=19)$ & $\mathrm{HTG}(\mathrm{N}=10)$ & $\mathrm{MD}(\mathrm{N}=53)$ & $\mathrm{P}$ \\
\hline Age (years) & $46.0 \pm 11.7$ & $50.2 \pm 12.9$ & $35.6 \pm 11.6$ & $46.2 \pm 10.3$ & 0.004 \\
BMI (kg/m $)$ & $27.5 \pm 3.6$ & $25.7 \pm 3.1$ & $27.3 \pm 3.6$ & $28.4 \pm 3.9$ & 0.041 \\
Waist $(\mathrm{cm})$ & $99.5 \pm 9.7$ & $96.2 \pm 10.3$ & $96.9 \pm 9.8$ & $101.2 \pm 9.2$ & 0.103 \\
Hip $(\mathrm{cm})$ & $97.9 \pm 6.3$ & $96.0 \pm 6.9$ & $96.0 \pm 7.6$ & $98.9 \pm 5.7$ & 0.141 \\
Baseline & & & & & \\
$\quad$ TC $(\mathrm{mg} / \mathrm{dL})$ & $243.0 \pm 42.1$ & $257.4 \pm 32.4$ & $175.5 \pm 17.4$ & $251.6 \pm 34.7$ & $<0.001$ \\
HDL-C (mg/dL) & $44.2 \pm 10.7$ & $53.4 \pm 11.6$ & $32.3 \pm 7.0$ & $42.9 \pm 7.8$ & $<0.001$ \\
LDL-C (mg/dL) & $163.9 \pm 48.7$ & $182.1 \pm 31.8$ & $122.0 \pm 66.4$ & $166.4 \pm 44.6$ & 0.004 \\
TG (mg/dL) & $234.7 \pm 128.4$ & $112.6 \pm 21.7$ & $245.6 \pm 79.5$ & $277.1 \pm 130.4$ & $<0.001$ \\
Follow-up & & & & & \\
$\quad$ TC $(\mathrm{mg} / \mathrm{dL})$ & $221.8 \pm 41.7$ & $226.3 \pm 32.9$ & $170.1 \pm 26.5$ & $227.9 \pm 43.1$ & $<0.001$ \\
HDL-C (mg/dL) & $42.3 \pm 9.4$ & $47.8 \pm 8.1$ & $31.7 \pm 5.5$ & $42.5 \pm 8.9$ & $<0.001$ \\
LDL-C (mg/dL) & $147.6 \pm 46.1$ & $152.6 \pm 32.2$ & $105.5 \pm 29.2$ & $153.5 \pm 49.3$ & 0.008 \\
TG (mg/dL) & $198.1 \pm 103.9$ & $127.5 \pm 43.8$ & $213.2 \pm 106.9$ & $220.6 \pm 108.6$ & $<0.001$ \\
\hline
\end{tabular}

A low-fat diet was eaten by the subjects for 6 to 8 weeks. $\mathrm{HC}=$ hypercholesterolemia; HTG = hypertriglyceridemia; $\mathrm{MD}=$ mixed dyslipidemia; $\mathrm{BMI}=$ body mass index; $\mathrm{TC}=$ total cholesterol; HDL-C = high-density lipoprotein cholesterol; LDL-C = low-density lipoprotein cholesterol; TG $=$ triglycerides. Statistical analyses for TG were performed on log-transformed variables using one-way ANOVA. All other analyses were carried out with one-way ANOVA. 
Table 2. Changes in lipid and lipoprotein concentrations after a 6- to 8-week lowfat dietary intervention as a function of type of dyslipidemia.

\begin{tabular}{lcc}
\hline & Baseline & Follow-up \\
\hline TC $(\mathrm{mg} / \mathrm{dL})$ & & \\
$\quad$ Total & $243.0 \pm 42.1$ & $221.8 \pm 41.7^{*}$ \\
HC & $257.4 \pm 32.4$ & $226.3 \pm 32.9^{*}$ \\
HTG & $175.5 \pm 17.4$ & $170.1 \pm 26.5$ \\
MD & $251.6 \pm 34.7$ & $227.9 \pm 43.1^{*}$ \\
HDL-C $(\mathrm{mg} / \mathrm{dL})$ & & \\
Total & $44.2 \pm 10.7$ & $42.3 \pm 9.4$ \\
HC & $53.4 \pm 11.6$ & $47.8 \pm 8.1^{*}$ \\
HTG & $32.3 \pm 7.0$ & $31.7 \pm 5.5$ \\
MD & $42.9 \pm 7.8$ & $42.5 \pm 8.9$ \\
LDL-C $(\mathrm{mg} / \mathrm{dL})$ & $163.9 \pm 48.7$ & $147.6 \pm 46.1^{*}$ \\
Total & $182.1 \pm 31.8$ & $152.6 \pm 32.2^{*}$ \\
HC & $122.0 \pm 66.4$ & $105.5 \pm 29.2$ \\
HTG & $166.4 \pm 44.6$ & $153.5 \pm 49.3$ \\
MD & & \\
TG $(\mathrm{mg} / \mathrm{dL})$ & $234.7 \pm 128.4$ & $198.1 \pm 103.9^{*}$ \\
Total & $112.6 \pm 21.7$ & $127.5 \pm 43.8$ \\
HC & $245.6 \pm 79.5$ & $213.2 \pm 106.9$ \\
HTG & $277.1 \pm 130.4$ & $220.6 \pm 108.6^{*}$ \\
MD &
\end{tabular}

Data are reported as means $\pm \mathrm{SD}$. $\mathrm{HC}=$ hypercholesterolemia $(\mathrm{N}=19) ; \mathrm{HTG}=$ hypertriglyceridemia $(\mathrm{N}=10) ; \mathrm{MD}=$ mixed dyslipidemia $(\mathrm{N}=53) ; \mathrm{TC}=$ total cholesterol; HDL-C = high-density lipoprotein cholesterol; LDL-C = low-density lipoprotein cholesterol; $\mathrm{TG}=$ triglycerides. ${ }^{*} \mathrm{P} \leq 0.05$ compared to baseline (Student paired $t$-test or the Wilcoxon signed-rank test for TG concentrations).

Table 3. Effect of CYP7A1 genotype distribution on the response of plasma lipids to a low-fat dietary intervention for 6 to 8 weeks.

\begin{tabular}{lccc}
\hline & \multicolumn{3}{c}{ CYP7A1 genotype } \\
\cline { 2 - 4 } & AA $(\mathrm{N}=27)$ & AC $(\mathrm{N}=40)$ & CC $(\mathrm{N}=15)$ \\
\hline Baseline & & \\
TC $(\mathrm{mg} / \mathrm{dL})$ & $246.4 \pm 47.9$ & $240.2 \pm 41.5$ & $244.3 \pm 33.9$ \\
HDL-C $(\mathrm{mg} / \mathrm{dL})$ & $44.6 \pm 12.2$ & $44.2 \pm 10.5$ & $43.5 \pm 9.0$ \\
LDL-C $(\mathrm{mg} / \mathrm{dL})$ & $170.5 \pm 53.0$ & $158.8 \pm 51.9$ & $165.9 \pm 28.9$ \\
TG $(\mathrm{mg} / \mathrm{dL})$ & $255.2 \pm 154.5$ & $235.4 \pm 118.6$ & $195.6 \pm 97.2$ \\
Follow-up & & & \\
TC $(\mathrm{mg} / \mathrm{dL})$ & $224.8 \pm 37.9$ & $219.6 \pm 43.4$ & $222.3 \pm 45.8$ \\
HDL-C $(\mathrm{mg} / \mathrm{dL})$ & $40.6 \pm 7.6$ & $43.1 \pm 11.1$ & $43.3 \pm 8.1$ \\
LDL-C $(\mathrm{mg} / \mathrm{dL})$ & $145.2 \pm 45.6$ & $144.6 \pm 45.2$ & $159.3 \pm 50.3$ \\
TG $(\mathrm{mg} / \mathrm{dL})$ & $231.3 \pm 97.1$ & $188.9 \pm 99.9^{*}$ & $163.4 \pm 116.1^{*}$ \\
Adjusted $\%$ of change & & & \\
TC & $-6.4 \pm 11.2$ & $-7.5 \pm 16.1$ & $-8.2 \pm 13.7$ \\
HDL-C & $-4.2 \pm 15.4$ & $-1.8 \pm 19.7$ & $-0.5 \pm 13.5$ \\
LDL-C & $-7.7 \pm 32.8$ & $-5.9 \pm 26.9$ & $-1.1 \pm 37.4$ \\
TGa & $-4.9 \pm 46.4$ & $-12.9 \pm 35.2^{*}$ & $-13.9 \pm 32.5^{*}$ \\
\hline
\end{tabular}

Data are reported as means \pm SD. aUnadjusted mean. Statistical analyses were performed on log-transformed variables. Baseline and follow-up lipid concentrations were adjusted by age and body mass index; adjusted \% of change values were adjusted by age, body mass index and the corresponding baseline lipid level. TC = total cholesterol; HDL-C = high-density lipoprotein cholesterol; LDL-C = low-density lipoprotein cholesterol; TG $=$ triglycerides. ${ }^{*} \mathrm{P}<0.04, \mathrm{AC}$ and $\mathrm{CC}$ compared to $\mathrm{AA}$. differed significantly between the HC, HTG and $\mathrm{MD}$ groups, the type of dyslipidemia was analyzed as a co-factor. Figure 1 describes the interaction between type of dyslipidemia and $-278 \mathrm{~A}>\mathrm{C}$ genotype on response to dietary intervention. The changes in total cholesterol concentrations for the $\mathrm{HC}$ and MD groups were similar among genotypes, whereas the HTG group showed a greater reduction in triglyceride concentrations when the $\mathrm{AA}$ and $\mathrm{AC}$ plus $\mathrm{CC}$ genotypes were compared $(P=0.027$ for type of dyslipidemia genotype interaction; Figure 1A). No interactions of HDL cholesterol, LDL cholesterol or triglyceride concentrations were observed (Figure 1B,C and D). For triglyceride concentrations, however, the effect of $-278 \mathrm{~A}>\mathrm{C}$ polymorphism was independent of type of dyslipidemia ( $P=$ 0.04; Figure 1D).

\section{Discussion}

It is well known that the effect of dietary changes on plasma lipid concentrations differs significantly between individuals. To clarify the mechanism of this association, we investigated the effect of the $-278 \mathrm{~A}>\mathrm{C}$ polymorphism in the CYP7A1 gene on the response of plasma lipids to changes of dietary fat intake in a group of dyslipidemic males.

Considering the patients as a whole, Table 2 shows that there were highly significant reductions in plasma total cholesterol, LDL cholesterol and triglyceride concentrations after dietary intervention. However, when the patients were divided into types of dyslipidemia, the changes in lipid concentrations were not similar. These data were expected, but indicate a probable confounding effect of type of dyslipidemia in the analysis shown in Table 3. However, when the type of dyslipidemia was analyzed as a co-factor, as shown in Figure 1, it was possible to demonstrate that the $-278 \mathrm{~A}>\mathrm{C}$ polymorphism had an effect on triglyceride response independently of the type of dyslipidemia.

The allele frequencies found in our study are comparable to those reported in the 
Table 4. Multiple linear regression analyses for follow-up triglyceride concentrations and adjusted percent triglyceride change.

\begin{tabular}{lcccc}
\hline & $\mathrm{R}^{2} \times 100$ & $\beta^{1}$ & $P$ & Partial $\mathrm{R}^{2} \times 100$ \\
\hline Follow-up TG (mg/dL) & \multirow{2}{*}{19.0} & & & \\
Age & & -0.113 & 0.273 & 1.2 \\
BMI & & 0.332 & 0.002 & 11.6 \\
CYP7A1 -278 AC or CC & & -0.216 & 0.041 & 5.2 \\
Adjusted \% of TG change & \multirow{2}{*}{30.7} & & & \\
Baseline TG concentrations & & 0.543 & $<0.001$ & 27.5 \\
Age & & 0.043 & 0.653 & 0.003 \\
BMI & -0.198 & 0.054 & 4.8 \\
CYP7A1 -278 AC or CC & & 0.224 & 0.023 & 6.2 \\
\hline
\end{tabular}

${ }^{1}$ Standardized coefficients. TG = triglycerides; $\mathrm{BMI}=$ body mass index.
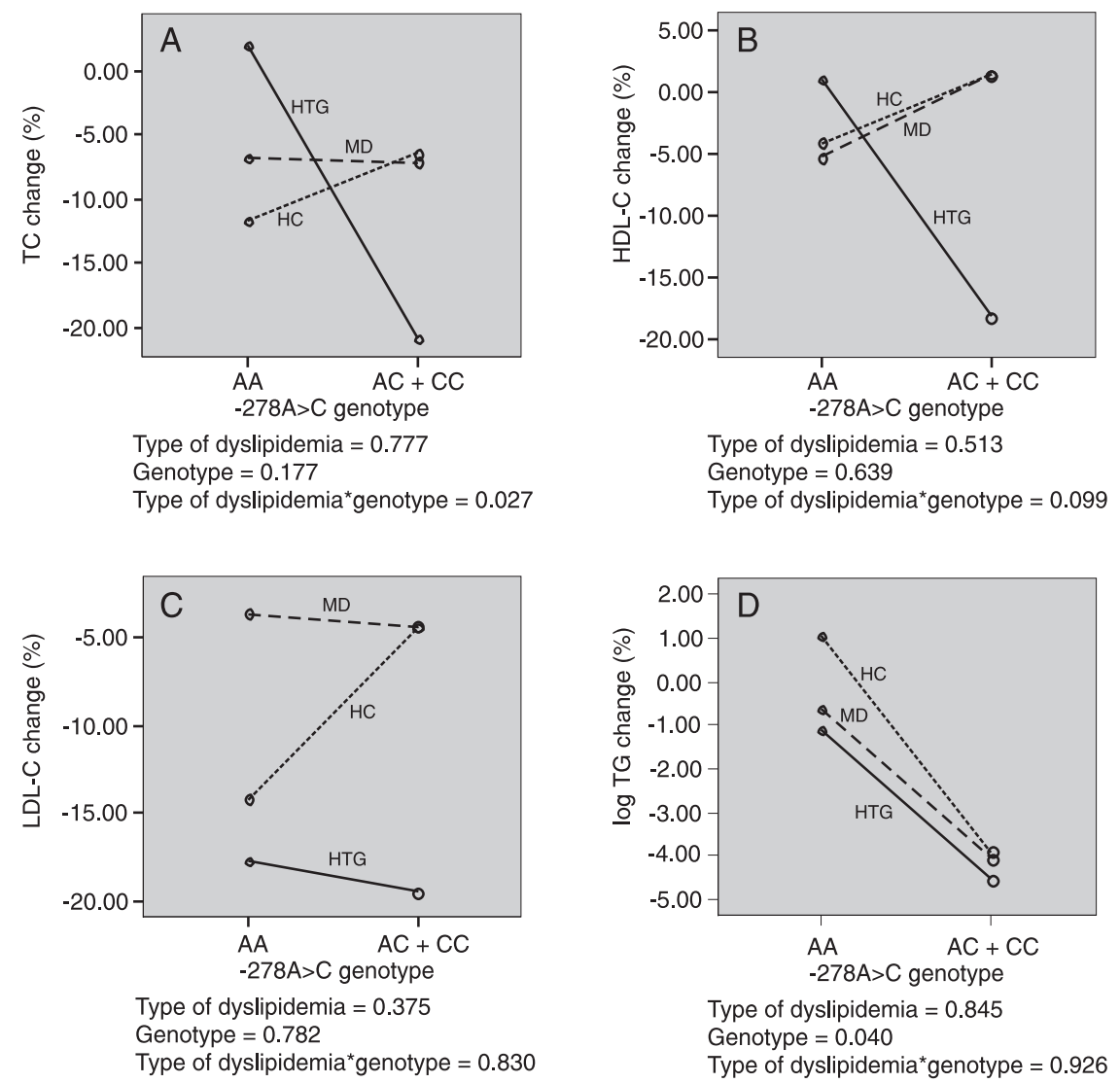

Figure 1. Adjusted means for changes (\%) in $A$, total cholesterol (TC); $B$, high-density lipoprotein cholesterol (HDL-C); $C$, low-density lipoprotein cholesterol (LDL-C), and $D$, log of triglyceride (TG) concentrations ( $\mathrm{mg} / \mathrm{dL})$, and the influence of the type of dyslipidemia [hypercholesterolemia $(\mathrm{HC})$, hypertriglyceridemia ( $\mathrm{HTG}$ ), and mixed dyslipidemia (MD)], $-278 \mathrm{~A}>\mathrm{C}$ genotypes (genotype), and the interaction of type of dyslipidemia and genotype (type of dyslipidemia*genotype) in patients with a 6- to 8-week low-fat diet. Only hypertriglyceridemic carriers of $-278 \mathrm{C}$ allele had significant reduction in TC concentrations (interaction type of dyslipidemia*genotype; $P=0.027$; Figure $1 \mathrm{~A})$. No significant association between genotypes and type of dyslipidemia and changes in HDL-C (Figure 1B) and LDL-C (Figure 1C) concentrations was observed. Carriers of $-278 \mathrm{C}$ allele showed significantly greater reductions in TG concentrations than AA homozygotes (genotype; $\mathrm{P}=0.04$ ), independent of type of dyslipidemia (interaction type of dyslipidemia* genotype; $\mathrm{P}$ $=0.926$; Figure 1D). 
literature for dyslipidemic individuals $(8,11,23)$. The main findings of our study were the association of CYP7A1 $-278 A>C$ polymorphism with lower triglyceride concentrations after modification of the $\operatorname{diet}(P=0.02)$ and with percentage of triglyceride changes after dietary intervention $(P=0.04$; Table 2). These findings agree with the literature that CYP7A1 activity may affect the triglyceride concentrations, since there is a strong correlation between bile acid synthesis and serum triglyceride concentrations $(2,24)$.

Previous studies have detected a link between triglyceride concentrations and $-278 \mathrm{~A}>\mathrm{C}$ polymorphism. Hofman et al. (11) found increased triglyceride concentrations in normolipidemic males with the AA genotype as compared to males with the CC genotype and a tendency towards increased concentrations of serum triglycerides, VLDL triglycerides and VLDL cholesterol in patients with hypertriglyceridemia. Couture et al. (6) showed that women homozygous for the $\mathrm{C}$ allele had significantly lower triglyceride concentrations than carriers of the A allele. Several lines of evidence indicate that the expression of CYP7A1 is hormonally regulated and its regulation is gender-dependent (25). Thus, further studies will be required to assess the gender-dependent relationship between plasma triglyceride concentrations and the CYP7A1 genotype.

Few studies about the associations of $-278 \mathrm{~A}>\mathrm{C}$ polymorphism of the CYP7A1 gene with plasma lipid responses to dietary variation have been conducted. In one study, Hubacek et al. (8) documented in a cohort of 131 men from the Czech MONICA study that subjects with the CC genotype had a significant decrease in plasma total cholesterol after a reduced dietary fat intake over an 8-year follow-up period. Interestingly, in a large cohort of men with coronary atherosclerosis, the CC genotype of the CYP7A1 -278A>C polymorphism was associated with increased progression of atherosclerosis and a possible risk of new cardiovascular events. After 2 years of treatment with pravastatin, the risk of a new clinical event appeared to be reduced in patients with the AA and AC genotypes, but not in patients with the CC genotype (14). These findings support the idea that individuals with CC genotypes could benefit most from a lipid lowering diet.

In the present study, no relationship was found between the $-278 A>C$ polymorphism of the CYP7A1 gene and plasma LDL cholesterol concentrations, in agreement with another report (26). In contrast, a previous study indicated that both men and women homozygous for the $\mathrm{C}$ allele had significantly elevated LDL cholesterol (23). In the Framingham Offspring Study, in which more than 2000 subjects were studied, the C-allele was associated with increased LDL cholesterol concentrations only in men, and allelic variability of the CYP7A1 gene accounted for $1 \%$ of the overall variation in plasma LDL cholesterol concentrations (6).

Kovar et al. (12), in a study on 11 healthy men, observed that the CC genotype responds to a high-fat diet by an increase in LDL and total cholesterol. Hofman et al. (9) observed in 104 and in 112 subjects that the CC genotype is associated with a higher response of plasma HDL cholesterol and total cholesterol after an increased intake of dietary cholesterol and cafestol, respectively.

The results obtained in the present study suggest that subjects with the $\mathrm{AC}$ or $\mathrm{CC}$ genotype will respond to dietary therapy with a significantly greater reduction in plasma triglyceride than individuals with the AA genotype. Furthermore, differences in dietary intake and diet composition could explain the discrepancies in the type of lipid change observed in different studies. Cheema et al. (27) reported that, in mice, the response of CYP7A1 to dietary cholesterol is dependent on the type of dietary fat.

Our findings also demonstrate that the $A C$ and $C C$ CYP7A1 genotypes contribute to 5.2 and $6.2 \%$ of triglyceride concentration during follow-up and adjusted percent of change of triglyceride concentration, respectively, accounting for a significant proportion of the genetic predisposition of the response of plasma lipid concentrations and the interindividual changes. However, due to the complex nature of gene-gene and gene-environmental interactions, we cannot exclude the possibility that our findings might be linked to another, functional, polymorphism in the CYP7A1 gene or in another unidentified gene near the CYP7A1 locus.

The main limitations of our study are its small sample size and the absence of follow-up of patient weight. However, the present study involved a prospective cohort and provided evidence that $-278 \mathrm{~A}>\mathrm{C}$ polymorphism in the CYP7A1 gene can modify triglyceride concentrations in response to dietary changes in a dyslipidemic male population with different types of dyslipidemia, with this gene representing a potential locus for the identification of responders during lipid-lowering diets and for a nutrigenetic directed approach.

\section{Acknowledgments}

We thank all of the patients who participated in the study. 


\section{References}

1. The Lipid Research Clinics Coronary Primary Prevention Trial results. I. Reduction in incidence of coronary heart disease. JAMA 1984; 251: 351-364.

2. The Lipid Research Clinics Coronary Primary Prevention Trial results. II. The relationship of reduction in incidence of coronary heart disease to cholesterol lowering. JAMA 1984; 251: 365-374.

3. Katan MB, Beynen AC, de Vries JH, Nobels A. Existence of consistent hypo- and hyperresponders to dietary cholesterol in man. Am J Epidemiol 1986; 123: 221-234.

4. Ye SQ, Kwiterovich PO Jr. Influence of genetic polymorphisms on responsiveness to dietary fat and cholesterol. Am J Clin Nutr 2000; 72: 1275S-1284S.

5. Lenicek M, Komarek V, Zimolova M, Kovar J, Jirsa M, Lukas M, et al. CYP7A1 promoter polymorphism -203A>C affects bile salt synthesis rate in patients after ileal resection. J Lipid Res 2008; 49: 2664-2667.

6. Couture P, Otvos JD, Cupples LA, Wilson PW, Schaefer EJ, Ordovas JM. Association of the A-204C polymorphism in the cholesterol 7alpha-hydroxylase gene with variations in plasma low density lipoprotein cholesterol levels in the Framingham Offspring Study. J Lipid Res 1999; 40: 18831889.

7. Hegele RA, Wang J, Harris SB, Brunt JH, Young TK, Hanley $\mathrm{AJ}$, et al. Variable association between genetic variation in the CYP7 gene promoter and plasma lipoproteins in three Canadian populations. Atherosclerosis 2001; 154: 579-587.

8. Hubacek JA, Pitha J, Skodova Z, Poledne R, Lanska V, Waterworth DM, et al. Polymorphisms in CYP-7A1, not APOE, influence the change in plasma lipids in response to population dietary change in an 8 year follow-up; results from the Czech MONICA study. Clin Biochem 2003; 36: 263-267.

9. Hofman MK, Weggemans RM, Zock PL, Schouten EG, Katan MB, Princen HM. CYP7A1 A-278C polymorphism affects the response of plasma lipids after dietary cholesterol or cafestol interventions in humans. J Nutr 2004; 134: 2200-2204.

10. Jiang ZY, Han TQ, Suo GJ, Feng DX, Chen S, Cai XX, et al. Polymorphisms at cholesterol 7alpha-hydroxylase, apolipoproteins $B$ and $E$ and low density lipoprotein receptor genes in patients with gallbladder stone disease. World J Gastroenterol 2004; 10: 1508-1512.

11. Hofman MK, Groenendijk M, Verkuijlen PJ, Jonkers IJ, Mohrschladt MF, Smelt AH, et al. Modulating effect of the A$278 \mathrm{C}$ promoter polymorphism in the cholesterol 7alphahydroxylase gene on serum lipid levels in normolipidaemic and hypertriglyceridaemic individuals. Eur J Hum Genet 2004; 12: 935-941.

12. Kovar J, Suchanek P, Hubacek JA, Poledne R. The A-204C polymorphism in the cholesterol 7alpha-hydroxylase (CYP7A1) gene determines the cholesterolemia responsiveness to a high-fat diet. Physiol Res 2004; 53: 565-568.

13. Hubacek JA, Bobkova D. Role of cholesterol 7alpha-hydroxylase (CYP7A1) in nutrigenetics and pharmacogenetics of cholesterol lowering. Mol Diagn Ther 2006; 10: 93100.
14. Hofman MK, Princen HM, Zwinderman AH, Jukema JW. Genetic variation in the rate-limiting enzyme in cholesterol catabolism (cholesterol 7alpha-hydroxylase) influences the progression of atherosclerosis and risk of new clinical events. Clin Sci 2005; 108: 539-545.

15. Kajinami K, Brousseau ME, Ordovas JM, Schaefer EJ. A promoter polymorphism in cholesterol 7alpha-hydroxylase interacts with apolipoprotein E genotype in the LDL-lowering response to atorvastatin. Atherosclerosis 2005; 180: 407-415.

16. Princen H, Post SM, Twisk J. Regulation of bile acid synthesis. Curr Pharm Design 1997; 3: 59-64.

17. Pullinger CR, Eng C, Salen G, Shefer S, Batta AK, Erickson SK, et al. Human cholesterol 7alpha-hydroxylase (CYP7A1) deficiency has a hypercholesterolemic phenotype. J Clin Invest 2002; 110: 109-117.

18. Santos RD. III Brazilian Guidelines on Dyslipidemias and Guideline of Atherosclerosis Prevention from Atherosclerosis Department of Sociedade Brasileira de Cardiologia. Arq Bras Cardiol 2001; 77 (Suppl 3): 1-48.

19. Executive summary of the Third Report of The National Cholesterol Education Program (NCEP) expert panel on detection, evaluation, and treatment of high blood cholesterol in adults (adult treatment Panel III). JAMA 2001; 285: 2486-2497.

20. Friedewald WT, Levy RI, Fredrickson DS. Estimation of the concentration of low-density lipoprotein cholesterol in plasma, without use of the preparative ultracentrifuge. Clin Chem 1972; 18: 499-502.

21. Lahiri DK, Nurnberger JI Jr. A rapid non-enzymatic method for the preparation of HMW DNA from blood for RFLP studies. Nucleic Acids Res 1991; 19: 5444.

22. Hagiwara T, Kono S, Yin G, Toyomura K, Nagano J, Mizoue $\mathrm{T}$, et al. Genetic polymorphism in cytochrome P450 7A1 and risk of colorectal cancer: the Fukuoka Colorectal Cancer Study. Cancer Res 2005; 65: 2979-2982.

23. Wang J, Freeman DJ, Grundy SM, Levine DM, Guerra R, Cohen JC. Linkage between cholesterol 7alpha-hydroxylase and high plasma low-density lipoprotein cholesterol concentrations. J Clin Invest 1998; 101: 1283-1291.

24. Qiao Y, Liu R, Bai H, Liu Y, Li X, Tang CW, et al. [Association between cholesterol 7alpha-hydroxylase -204A/C gene polymorphism and endogenous hypertriglyceridemia in Chinese]. Zhonghua Yi Xue Yi Chuan Xue Za Zhi 2007; 24: 432-436.

25. Russell DW, Setchell KD. Bile acid biosynthesis. Biochemistry 1992; 31: 4737-4749.

26. Abrahamsson A, Krapivner S, Gustafsson U, Muhrbeck O, Eggertsen G, Johansson I, et al. Common polymorphisms in the CYP7A1 gene do not contribute to variation in rates of bile acid synthesis and plasma LDL cholesterol concentration. Atherosclerosis 2005; 182: 37-45.

27. Cheema SK, Cikaluk D, Agellon LB. Dietary fats modulate the regulatory potential of dietary cholesterol on cholesterol 7 alpha-hydroxylase gene expression. J Lipid Res 1997; 38: 315-323. 